\title{
Level of knowledge of small-scale milk producers on bovine tuberculosis (Mycobacterium bovis) in selected parts of Chongwe district
}

\author{
Emmanuel Chileshe ${ }^{1,2}$ \\ 1. Department of Public Health, School of Medicine, University of Zambia, Lusaka, Zambia; 2. Department of Veterinary \\ Services, Mumbwa, Zambia. \\ Corresponding author: Emmanuel Chileshe, e-mail: emmanuel_chileshe@yahoo \\ Received: 02-07-2017, Accepted: 27-11-2017, Published online: 25-12-2017
}

doi: 10.14202/IJOH.2017.83-86 How to cite this article: Chileshe E. Level of knowledge of small-scale milk producers on bovine tuberculosis (Mycobacterium bovis) in selected parts of Chongwe district. Int J One Health 2017;3:83-86.

\begin{abstract}
Aim: This study was intended to establish the level of knowledge of small-scale milk producers on bovine tuberculosis (BTB), one of the neglected zoonotic diseases.

Materials and Methods: In this study, a descriptive cross-sectional survey design was used. A total of 369 small-scale milk producers were interviewed using a pretested interviewer questionnaire. Using a computer, data obtained from the operator-administered questionnaires were entered in Epidata ${ }^{\circledR}$ and exported to Stata $10.0^{\circledR}$ for analysis with which descriptive statistics were generated for analysis. The level of knowledge on BTB for both male and female small-scale milk producers was analyzed in relation to membership to cooperative, frequency of TB tests in cattle, availability of extension services, and milk handling and utilization practices. The relationships between the different hypothesized confounders and the binary outcome (BTB testing) were investigated with Pearson's Chi-squared test for association. Logistic regression model describing the BTB cattle testing among the farmers controlling for hypothesized confounders was finalized using likelihood ratio testing to screen the significance of posited confounders in the model. To ensure validity and eliminate bias of data, the interviews were limited to three interviewers. The questionnaires were pre-tested for clarity as well as to avoid confounding questions.
\end{abstract}

Results: Majority (95\%) of the small-scale milk producers across the study had heard about BTB. The proportion of those who knew that it is transmittable to humans was low $(43.8 \%)$. The proportion of those who knew its mode of transmission to humans was also low (32.4\%). However, it was high in milk producers belonging to dairy cooperatives followed by producers in livestock cooperatives. It was noted that a small proportion of small-scale milk producers ensured that their cattle were tested for BTB. Logistic regression showed that there was 73 times likelihood that small-scale milk producers belonging to dairy cooperatives will have their cattle tested for BTB.

Conclusion: The study established a low level of knowledge on BTB transmission and prevention. It also concluded that few cattle in the small-scale milk production sector get tested for BTB and that the level of knowledge of the milk producers on BTB, in this sector, is associated with this.

Keywords: bovine tuberculosis, Mycobacterium bovis, veterinary extension.

\section{Introduction}

Tuberculosis (TB) is a chronic infectious granulomatous airborne bacterial disease of poverty, affecting mostly young adults in their most productive years [1]. It is estimated that $95 \%$ of deaths due to TB occur in developing countries [2,3]. In 2015, there were an estimated 10.4 million new TB cases worldwide [2]. Human TB is commonly caused by a bacterium, Mycobacterium tuberculosis, though a proportion of cases are due to Mycobacterium bovis, found in cattle [4]. TB due to M. bovis, commonly referred to as bovine tuberculosis (BTB), is indistinguishable from that caused by M. tuberculosis [5].

Copyright: Chileshe. This article is an open access article distributed under the terms of the Creative Commons Attribution 4.0 International License (http://creativecommons.org/licenses/ by/4.0/), which permits unrestricted use, distribution, and reproduction in any medium, provided you give appropriate credit to the original author(s) and the source, provide a link to the Creative Commons license, and indicate if changes were made. The Creative Commons Public Domain Dedication waiver (http:// creativecommons.org/ publicdomain/zero/1.0/) applies to the data made available in this article, unless otherwise stated.
Infection of humans with $M$. bovis is mainly through contaminated milk and is characterized not by a pulmonary infection but by a cervical lymphadenitis [6]. Many epidemiological and public health aspects of $M$. bovis remain largely unknown and therefore should be treated as a risk organism group III with appropriate precaution to prevent infection occurring in humans [7].

Many humans are not aware of the risk factors associated with the transmission of BTB and their living conditions often promote the zoonotic spread of the disease [8]. Lack of awareness of milk-borne zoonoses such as BTB can put the lives of milk consumers, producers, farm workers, and members of their households at risk of infection [9]. A recent Department for International Development funded report of 2012 suggests an average of $10.5 \%$ of human TB cases being associated with M. bovis in developing countries [10].

Smallholder milk production is increasingly dominating the dairy industry in eastern and southern parts of Africa [11]. Zambia's dairy sector is estimated to produce over 253 million liters of milk annually, with only 44 million liters passing through formal 
market channels [12]. In the small-scale milk production sector, where $M$. bovis gets little attention as a public health threat, milk is usually marketed directly to consumers through open air markets and does not enter the commercial channels for processing [13].

In a study conducted in Zimbabwe to determine the awareness levels of small-scale milk producers on zoonotic diseases, Mosalagae et al. pointed to remoteness, lack of health facilities, poor extension services, low training on cattle handling and low literacy levels as major contributors to low awareness among smallholder dairy farmers from African countries [9]. Therefore, improvement in dairy husbandry practices, education of public on the mode of transmission and prevention, and also collaboration between medical and veterinary professionals could be highlighted as some of the solutions to reducing the danger posed by M. bovis [14].

The objectives of the study were to describe the level of knowledge of small-scale milk producers on BTB (M. bovis) and to investigate milk utilization and hygiene practices of small-scale milk producers in selected parts of Chongwe District.

\section{Materials and Methods}

\section{Ethical approval/informed consent}

Informed consent was sought from respondents and also assurance was given to them that confidentiality was going to be maintained in the study, by assigning them codes. In addition, approval of the research was sought from a mandated ethics committee (Eres converge). Permission to conduct this study in Chongwe District was also obtained from Chongwe District Council.

\section{Study area description}

The research was conducted in selected parts of Chongwe District of Zambia. The district is located on the eastern part of Lusaka Province. The district has 138,632 people, with a total of 27,845 households scattered in ten political wards. The district has a total of five veterinary camps. The district was selected because of its growing small-scale milk production sector, which is a potential supplier of milk to the big market of Lusaka.

\section{Study design}

The study employed a descriptive cross-sectional study design.

\section{Data collection}

Data were collected using an interviewer-administered questionnaire.

\section{Statistical data storage and analysis}

Using a computer, data obtained from operator-administered questionnaires were entered in Epidata $^{\circledR}$ (Lauritsen and Bruus, 2003) and exported to Stata $10.0^{\circledR}$ (StataCorp, 2008) for analysis with which descriptive statistics were generated for analysis.

The relationships between the different hypothesized confounders and the binary outcome (BTB testing) were investigated with Pearson's Chi-squared test for association. Logistic regression model describing the BTB cattle testing among the farmers controlling for hypothesized confounders was finalized using likelihood ratio testing to screen the significance of posited confounders in the model.

\section{Results}

\section{Respondents with correct knowledge about BTB and its transmission}

Respondents were asked key questions about BTB. Majority (95\%) said they had heard about BTB in cattle. Out of these, almost half (43.8\%) thought that the disease was able to be transmitted to humans from cattle. Fewer of the respondents $(32.4 \%)$ knew that BTB could be transmitted through consumption of raw milk. Of milk producers belonging to dairy cooperatives, $87.1 \%$ indicated that they had heard about BTB, while only $78.1 \%$ of those in livestock cooperatives had heard about BTB (Table-1).

\section{Respondents with correct knowledge on BTB prevention}

It was established from the current study that majority of small-scale milk producers $(95 \%)$ believed that BTB transmission to cattle and humans can be prevented by eliminating cattle that are BTB positive.

Table-1: Responses about bovine tuberculosis.

\begin{tabular}{|c|c|c|c|}
\hline Risk question & Milk producer category & $n$ & Prevalence of knowledge \\
\hline \multirow{5}{*}{ Heard of tuberculosis in cattle } & Total & 361 & $(95 \%)$ \\
\hline & Livestock coop only & 41 & $78.1(65.2-91.0)$ \\
\hline & Agriculture coop only & 245 & $28.2(22.5-33.8)$ \\
\hline & Dairy coop only & 31 & $87.1(75.1-99.1)$ \\
\hline & No coop & 44 & $35.0(22.8-47.2)$ \\
\hline \multirow[t]{5}{*}{ Said BTB is transmitted to humans } & Total & 158 & $(43.8 \%)$ \\
\hline & Livestock coop only & 32 & 100 \\
\hline & Agriculture coop only & 76 & $56.5(45.3-67.9)$ \\
\hline & Dairy coop only & 27 & $81.5(66.4-96.5)$ \\
\hline & No coop & 12 & 73.9 (55.4-92.4) \\
\hline \multirow[t]{5}{*}{ Said BTB is transmitted via raw milk } & Total & 117 & $(32.4 \%)$ \\
\hline & Livestock coop only & 32 & $96.9(90.7-100)$ \\
\hline & Agriculture coop only & 46 & 76.1 (63.5-88.7) \\
\hline & Dairy coop only & 22 & $81.8(65.2-98.5)$ \\
\hline & No coop & 7 & $76.5(55.5-97.5)$ \\
\hline
\end{tabular}

BTB $=$ Bovine tuberculosis 
However, a smaller proportion (41.6\%) thought that testing cattle for BTB would prevent it.

\section{Frequency of veterinary extension services to respondents}

On veterinary extension services, it was established that small-scale milk producers were not visited as frequent as would be expected, i.e. 8 times a year, to sensitize them about various livestock and zoonotic diseases.

\section{Sources of information on BTB awareness}

On the sources of information about BTB, majority $(58.2 \%)$ of respondents said that they obtained information about BTB through reading literature. Nearly $24.1 \%$ of respondents said that they obtained information through interaction with veterinary extension staff while $15.8 \%$ said that they obtained it through health workers. About $10.8 \%$ of respondents mentioned television as their source of information.

\section{Discussion}

The current study established that most (95\%) of the small-scale milk producers had heard about BTB. Unfortunately, a majority $(56.2 \%)$ of them did not know that BTB could be transmitted to humans. In addition, most $(67.6 \%)$ of them did not know that transmission could occur through consumption of raw milk. A similar study in Ethiopia found that a low proportion of respondents $(25.7 \%)$ understood that BTB is zoonotic [15] while another study in the same country, by Ameni et al., also found a low (34\%) proportion of respondents who thought of milk as a source of infection for BTB [11].

When grouped according to cooperatives, small-scale milk producers belonging to dairy cooperatives had high $(83.5 \%)$ prevalence of knowledge on BTB including mode of transmission, followed by those in livestock cooperatives. This result could be explained by the fact that dairy cooperatives are actively involved in selling milk to milk processing companies who place a lot of emphasis on milk quality. Therefore, it is possible that they may have come across information related to milk-borne diseases, during interactions with milk processing companies, thereby acquiring information about BTB. This is supported by a study in the Kafue basin in Zambia, which concluded that cattle owners who had prior exposure to BTB connected activities such as screening of cattle had more knowledge on prevalence, transmission, and control of BTB [16].

Similarly, from the logistic regression analysis, milk producers who had their cattle tested for BTB were more likely to have more knowledge about transmission of BTB and therefore its importance in this industry. Thus, the frequency of BTB tests in cattle is an indication of the level of extension services and therefore a proxy to explaining the level of knowledge of milk producers.

The Department of Veterinary Services, under the Ministry of Agriculture and Livestock, is charged with the responsibility of providing veterinary services including veterinary public health services. These include safeguarding the public from diseases such as rabies and $\mathrm{BTB}$, through vaccinations and sensitization of communities about prevention of the various zoonotic diseases. Therefore, it is through such systems that milk producers are supposed to be enlightened about risks posed by selling of raw milk from cattle not certified to be BTB free to the public. The evidence of low number of visits by extension workers to the milk producers would suggest low sensitization of smallscale milk producers about BTB and the importance of testing their cattle for BTB. This leads to the low understanding of BTB transmission to humans and the low number of BTB tests in the small-scale milk sector, as has been established in the current study.

The study established that milk producers obtained BTB information mainly through reading literature, secondly through veterinary extension staff and thirdly through health workers. Television also played a role in this context. This finding in the current study is similar to the finding in a study in Malawi which observed that more than half of the milk producers received information about zoonotic diseases through agriculture extension workers, followed by medical staff and through formal education [17].

With the foregoing, it is suggested that government veterinary and health staff should increase the level of collaboration in sharing information and in sensitizing milk producers about BTB and its risks, which are related to milk handling. This will ensure effective protection of the public from BTB infection and the promotion of the One Health concept in the field of Public Health in Zambia.

\section{Conclusion and Recommendations}

According to the results, animal health workers play a leading role in transferring information to milk producers, therefore highlighting a need to ensure that knowledge about zoonotic diseases is passed through efficient animal health extension services. Since these extension services are sometimes hampered by inadequate resources, relaying information through more focused groups such as cooperatives would help in maximizing the utilization of available limited resources for extension services. In designing interventions such as increasing level of knowledge among milk producers and prevention of BTB infections to cattle and humans, the use of dairy and livestock cooperatives as points of implementation should be considered.

The findings in this research highlight the need for effective public health systems, providing for mandatory screening of cattle in the small-scale milk production sector, for BTB, supported by both government and private sectors. Munyeme et al. suggested the need for disease awareness campaigns in the form of farmer education, farmer-supported actions, and farmer participation in disease extension activities and that farmer participation in these activities will develop farmers' interest in assisting disease control 
experts such as those in the public health sector, to prevent or control zoonoses such as BTB [16].

There is also a serious need for public health inspectors to extend their inspections beyond just meat inspections to milk, especially in the small-scale milk production sector as the milk industry grows. The inspections shouldinclude checking whether milk producing cattle are tested for BTB. This will ensure that BTB-positive cattle are eliminated from the sector, therefore giving an assurance that milk to the market is safe from contamination with BTB.

The information from this research is important for policymakers in planning interventions or implementing mitigation measures in BTB prevention and also in dealing with other neglected zoonotic diseases. As the dairy industry is projected to grow in Zambia and the vulnerability of milk consumers to BTB remains high, especially among those with HIV/ AIDS, which stands at $14.3 \%$ prevalence, determining the levels of awareness of milk producers is cardinal if public health is going to be assured.

As a way forward, more epidemiological studies are needed in this area to determine BTB prevalence in cattle and to try and isolate $M$. bovis in identified TB cases in humans in Chongwe District and other parts of the country, as there is very little or no information on these. Also, most of the available information about BTB in Zambia was obtained through research conducted many years ago and therefore maybe outdated, justifying further research as dynamics may have changed.

\section{Author's Contributions}

EC conducted the research in Chongwe District and later entered the data in Epidata Software. EC further analyzed the data and then drafted and revised the article. The results were discussed with the author's supervisor. The author produced the final manuscript.

\section{Acknowledgments}

Special thanks go to the Almighty God Jehovah, for keeping me alive and giving me the strength to go on. Special thanks also go to my supervisors Dr. Musso Munyeme, Dr. Celestine Nzala, and Dr. Rose N. Likwa for their guidance and support during the whole process of this study. Their ability to create time for me to consult them on various aspects of my research, despite their busy daily engagements, was not only a demonstration of their personal dedication to the development of others, but also a reflection of the contribution of the University of Zambia to the development of our country, Zambia. This study and indeed the whole academic process would not have been a reality without funding from the Department of Veterinary Services, and in particular, the Director of Veterinary Services, Dr. Joseph Mubanga, the Chief Veterinary Officer, Dr. Francis Mulenga, and the Principal Veterinary officer in charge of Public Health, Dr. Mathew Kabeta, whose support facilitated the successful research data collection and analysis processes.

\section{Competing Interests}

The author declare that he has no competing interests.

\section{References}

1. Suzen EA. Merck Veterinary Manual. NJ, USA: Merck \& Co. in Cooperation with Merial Ltd.; 1998.

2. World Health Organization. Tuberculosis Global Facts. Geneva: World Health Organization; 2017.

3. Ayele WY, Neill SD, Zinsstag J, Weiss MG, Pavlik I. Bovine tuberculosis : An old disease but a new threat to Africa. Vet Res 2004;8:924-37.

4. Cosivi O, Grange JM, Daborn CJ, Raviglione MC, Fujikura T, Cousins D, et al. Zoonotic tuberculosis due to Mycobacterium bovis in developing countries. Emerg Infect Dis 1998;4:59-70.

5. Humblet M, Boschiroli ML, Saegerman CS. Review article classification of worldwide bovine tuberculosis risk factors in cattle : A stratified approach. Vet Res 2009;40:50.

6. Shitaye JE, Tsegaye W, Pavlik I. Bovine tuberculosis infection in animal and human populations in Ethiopia: A review. Vet Med 2007;52:317-32.

7. Organization for International Epizootics (O.I.E). Terrestrial Manual: World Assembly of Delegates. Paris Organization for International Epizootics (O.I.E); 2009.

8. Mc Geary, A. The role of Mycobacterium bovis in Africa. Med J Ther Afr 2008;2:59-62.

9. Mosalagae D, Pfukenyi DM, Matope G. Milk producers' awareness of milk-borne zoonoses in selected smallholder and commercial dairy farms of Zimbabwe. Trop Anim Health Prod 2011;43:733-9.

10. Grace D, Mutua F, Ochungo P, Kruska R, Jones K, Brierley L, et al. Mapping of Poverty and Zoonoses Likely Hotspots Report; Project 4, Funded by DFID. Nairobi, Kenya: International Livestock Research Institute; 2012.

11. Ameni G, Erkihun A. Bovine tuberculosis on small-scale dairy farms in Adama town, central Ethiopia, and farmer awareness of the disease. Rev Sci Tech 2007;26:711-9.

12. Mumba C, Pandey GS. Assessment of Opportunities for Improving Dairy Production, Marketing, and Adoption of Good Animal Husbandry Practices within Traditional Cattle Keeping Areas of Zambia. Zambia: SNV Dairy Study; 2012.

13. Hachaambwa M, Hantuba H, Nawiko M. Trends in Growth of Modern Retail and Wholesale Chains and Related Agribusiness. Information Sheet I. Zambia; 2007.

14. Demelash B, Inangolet F, Oloya J, Asseged B, Badaso M, Yilkal A, et al. Prevalence of bovine tuberculosis in Ethiopian slaughter cattle based on post-mortem examination. Trop Anim Health Prod 2009;41:755-65.

15. Tigre W, Alemayehu G, Abetu T, Deressa B. Preliminary study on the epidemiology of bovine tuberculosis in Jimma town and its surroundings, South-western Ethiopia. Glob Vet 2011;6:369-73.

16. Munyeme M, Muma J, Mungandu H, Kankya C, Skjerve E, Tryland M, et al. Cattle owners' awareness of bovine tuberculosis in high and low prevalence settings of the wildlife-livestock interface areas in Zambia. BMC Vet Res 2010;6:21.

17. Tebug S. Factors associated with milk producer's awareness and practices in relation to zoonoses in northern Malawi. Vet World 2013;6:249. 